\title{
"Você precisa falar português com seu filho" \\ Desafios para o processo de inclusão de crianças imigrantes em escolas do Rio de Janeiro
}

\author{
Adriana Maria Assumpção ${ }^{1}$ (D) @ \\ Gabriela de Azevedo Aguiar ${ }^{1}$ (B) @ \\ ${ }^{1}$ Universidade Estácio de Sá (UNESA), Brasil.
}

\begin{abstract}
Mãe, você precisa falar mais português com seu filho. Por isso ele não está aprendendo a ler. Você fala muito espanhol.

("R" professora de Leandro, ao se dirigir à sua mãe, Juliana, peruana casada com um equatoriano)
\end{abstract}

Resumo. O presente trabalho apresenta uma reflexão teórica sobre a inclusão de crianças imigrantes no contexto escolar brasileiro, particularmente, em escolas do Rio de Janeiro. Abordamos a legislação pertinente e as práticas de espaços de educação formal, a partir das narrativas de crianças e suas respectivas mães. Nosso interesse é suscitar reflexões para a compreensão da questão do direito das crianças imigrantes à educação, considerando acesso e inclusão, como pontos fundamentais nesta discussão.

Palavras-chave: educação; inclusão; crianças imigrantes; migração transnacional.

"Tienes que hablar portugués con tu hijo". Retos para el proceso de inclusión de los niños inmigrantes en las escuelas de Río de Janeiro

Resumen. En el presente trabajo se hace una reflexión teórica sobre la inclusión de niños inmigrantes en el ámbito educativo brasileño, especialmente en las escuelas de Río de Janeiro. Abordamos la legislación pertinente y la práctica de espacios de educación formal, a partir de los relatos de los niños y de sus respectivas madres. Nuestro interés es plantear reflexiones para comprender el tema del derecho a la educación de los niños migrantes y hacer del acceso y la inclusión elementos fundamentales de este debate..

Palabras clave: educación; inclusión; niños inmigrantes; migración transnacional.

"You need speak portuguese with your son". Challenges for the inclusion of immigrant children in the scholls in Rio de Janeiro

Abstract. This paper presents a theoretical reflection about the inclusion of immigrant children in the Brazilian school context, particularly in schools in Rio de Janeiro. We approach the relevant legislation and practices in formal education settings, from the narratives of children and their respective mothers. Our interest is to raise reflections on the issue of the right of immigrant children to education, considering access and inclusion, as fundamental points in this discussion.

Keywords: education; inclusion; immigrant children; transnacional migration.

\section{Introdução}

Como compreender os desafios para a inclusão das crianças imigrantes na escola, bem como o papel das mães nessa relação e no diálogo com a equipe que atua neste espaço (professor/a e equipe de gestão escolar)?

Por meio de vivências com crianças imigrantes oriundas de diversos países, bem como seus pais, e no contato com professores das redes pública e privada estudantes do curso de especialização "Construindo a Inclusão em 
Educação", da Faculdade de Educação da Universidade Federal do Rio de Janeiro, a proposta deste texto é refletir sobre o direito das crianças imigrantes à educação, considerando acesso e inclusão, como pontos fundamentais nesta discussão, pois as dificuldades são inúmeras no que diz respeito ao estudante, mas também em relação à equipe pedagógica da instituição escolar que o recebe. Trata-se de um recorte da pesquisa que está sendo desenvolvida no grupo DIASPOTICS ${ }^{1}$ sobre infância e migrações transnacionais. Por meio da análise das narrativas de crianças e de suas mães, buscamos problematizar esta questão e refletir acerca do processo de inclusão. Nosso recorte de pesquisa, trazendo as narrativas das mães, se deve ao fato de estarmos trabalhando com crianças equatorianas e, neste grupo social a relação foi estabelecida com as mulheres. Em nossa percepção, a aproximação com as mulheres e o distanciamento dos pais das crianças está relacionada com a maneira como este grupo se organiza, com preceitos de uma sociedade de estrutura fortemente patriarcal e isto foi demonstrado por essas mulheres em diferentes ocasiões. Na tentativa de exemplificar uma dessas narrativas, recordamos um momento de conversa com uma delas perguntamos como era a vida cotidiana e como se dava a participação dos homens (maridos e pais das crianças). A narrativa que apresentamos a seguir, é de Renata (28 anos, casada com um equatoriano e mãe de um filho) traduz de forma muito clara como é a organização diária das tarefas.

Como es la rutina? Quieres saber como hacemos las tareas? Somos nosotros quienes nos encargamos de eso, lo llevamos a la escuela, hacemos los deberes que envía la professora...y seguimos trabajando como ambulantes tanto como ellos. Um día descubrí que tenía uma mujer em la calle que trabajaba em Tijuca. ${ }^{2}$.. le dije que iba a trabajar y que él tendría que cuidar a nuestro hijo. Sabes lo que pasó? Cuando llegué a casa no tenia comida...mi hijo estaba em la casa de um amigo y mi esposo fue a beber com amigos...

A orientação da professora à mãe equatoriana, colocada no início do texto, deu início a um processo conjunto de reflexão das autoras sobre o apoio aos professores das redes municipal e estadual de educação do Rio de Janeiro, já que entendemos, como Grinberg e Grinberg (1996, p.101), que "Las características del lenguaje contienen una Weltanschaung definida que determina la manera en que percibimos y aprehendemos la realidad".

${ }^{1}$ DIASPOTICS é um grupo de pesquisa vinculado à Escola de Comunicação da UFRJ (ECO) e ao Programa de Pós-Graduação em Psicossologia de Comunidade e Ecologia Social da UFRJ (EICOS). Coordenado pelo Prof. Dr. Mohammed ElHajji, tem uma proposta de apreensão, análise e compreensão do fenômeno migratório e diaspórico a partir dos fluxos e rastros subjetivos produzidos pelo imigrante e as comunidades diaspóricas. https:// diaspotics.org/

${ }^{2}$ Tijuca é um bairro localizado na zona norte da cidade do Rio de Janeiro. 
Nesse sentido, se a língua é tão fundamental em nossa estrutura de compreensão do mundo, como entender o que é solicitado para esta mãe? Como a mãe percebe este pedido da professora? Talvez possamos inferir que esta progenitora, bem como outras mães de origem estrangeira compreendem como Schaff (1969), que "o sujeito é um dos elementos mais tradicionais da cultura, o mais resistente a mutações" (apud Grinberg, \& Grinberg, 1996, p. 101).

Dessa maneira, as autoras, enquanto profissionais preocupadas com a questão da inclusão, decidiram investigar este processo, unindo os esforços das visões da pedagogia e da psicossociologia, complementares e pertinentes ao trabalho aqui apresentado.

O texto está organizado em partes distintas, a saber: a primeira apresenta a revisão da literatura, enfocando a legislação brasileira no tocante ao direito de toda criança à educação. Na segunda parte apresentamos o cenário empírico e a metodologia da pesquisa. Por último, tecemos considerações sobre o tema da pesquisa e apresentamos alguns resultados preliminares, em virtude de se tratar de um estudo em desenvolvimento.

\section{Desenvolvimento}

Nobody can take away what we carry inside (María apud Yousafzai \& Welch, 2019, p. 117)

Um imigrante é aquele que se muda em um país estrangeiro, buscando trabalho, residência ou movido por relações amorosas. Essa palavra foi formada a partir do particípio latino imigrans, formado por in+migro. In como na língua portuguesa, é uma preposição que indica movimento de fora para dentro e migro é um verbo que se relaciona a deslocamentos de um lugar para outro; Imigrar deriva do latim migrare, que significa "mudar de posição".

Os filhos(as) de imigrantes não escolheram essa condição, pois são forçados a deixar seus lares, suas referências, seus amigos e raízes em função da necessidade e/ou desejo que seus pais tiveram em buscar um país "melhor" e com mais oportunidades, ainda que houvesse a condição de provisório, naquilo que se torna na maior parte das vezes, definitivo em suas vidas.

"Trazemos oceanos circulando entre nós", escreveu Mia Couto no livro Terra Sonâmbula. Trata-se de uma história que fala sobre a terra amada, vagar sobre ela, deixá-la para não morrer de saudade - mas, ao mesmo tempo, retê-la na lembrança. A terra onde se nasce é a infância. Para os que 
migram, essa infância deve subitamente criar pés e se descolar. Quando se é criança, atravessar os mares é mais fácil, porque há esperança, ou o quintal é um lugar querido para se abandonar? (Garcia, 2015) ${ }^{3}$

As crianças representam um número expressivo no que diz respeito ao total de imigrantes e refugiados em todo o mundo e, particularmente no Brasil, este número vem aumentando nos últimos anos ${ }^{4}$. A migração de crianças chega a corresponder à metade do total de imigrantes que estão vivendo em nosso país. Crianças são também mais vulneráveis no processo migratório e necessitam de auxílio específico dos adultos em sua adaptação. Podemos enumerar muitas dificuldades encontradas, a começar pelas barreiras linguísticas e por questões de cunho emocional (estranhamento com os hábitos comportamentais do novo país, discriminação pelas outras crianças em função das visões estereotipadas que muitas elas possuem a respeito dos imigrantes). A necessidade de pertencimento tem implicações no desenvolvimento emocional e cognitivo das crianças - e de seus pais/responsáveis, assim como a saudade da pátria, que influencia sua adaptação no contexto escolar. É preciso lembrar que seus pais/responsáveis estão - eles mesmos -imersos nos próprios processos de imigração, que podem desencadear diversas crises, como "ameaças ao sentimento de identidade", como explicam Grinberg e Grinberg (1996, p. 127), o que faz com que o suporte que poderiam dar aos filhos em outras situações esteja comprometido ou bastante abalado.

No entanto, muitas vezes os adultos - tanto equipe pedagógica quanto os próprios pais e responsáveis pelas crianças - não estão atentos ou desconhecem fatores que influenciam um processo que leva em consideração o bem-estar mental da criança e sua família. O senso comum de que as crianças facilmente se adaptam com as novas experiências e lugares, desconsidera esses desafios. Essa concepção de plasticidade da criança e facilidade é ainda maior em relação aos primeiros anos de vida. Não é uma visão somente brasileira, já que podemos perceber nos Estados Unidos a mesma concepção, como colocam Park e Katsiaficas (2019):

The first five years of a child's life are a time of exceptional growth and development, and one that can be profoundly influenced by traumatic experiences. A well-established body of research now firmly refutes the commonly held belief that infants and toddlers are "too young" to be affected by traumatic events, calling for interventions and support to mitigate their documented negative impacts. However, while awareness of childhood trauma has increased among policymakers and service providers,

\footnotetext{
${ }^{3}$ https://bit.ly/2m0I50t

${ }^{4}$ Dados ACNUR 2017
} 
discussions of how the early childhood education and care field should adapt often overlook the unique experiences of children in immigrant and refugee families. (p.2)

E como dar esse apoio às crianças e suas famílias, já que o tabu da saúde mental é ainda forte no país e a maior parte das escolas existentes no Rio de Janeiro não possui psicólogo em sua equipe?

Em se tratando de imigração, nos parece pertinente considerar a premissa de Escudero (2017, p. 150) ao ressaltar que "falar da imigração é discorrer sobre a sociedade como um todo, seja a partir de uma perspectiva histórica, seja a partir das estruturas presentes da sociedade e de seu funcionamento". A escola pública brasileira possui inúmeros problemas em sua estrutura e na forma de atender a sociedade, dessa maneira, os docentes, muitas vezes, enxergam o aluno imigrante como um "problema" naquele contexto.

Em alguns casos, são realizados "diagnósticos" precipitados das crianças imigrantes, onde os próprios professores passam a nomeá-las como disléxicos, portadores de déficit de atenção ou outros transtornos relacionados ao desenvolvimento infantil (Bonadio, 2013; Galina,Silva, Haydu, Martin, 2017) e podemos relacionar essa situação com as crianças portadoras de necessidades especiais que precisam de um trabalho pedagógico específico, entretanto, muitas vezes não recebem este atendimento e são excluídas do processo educativo. A premissa do trabalho neste contexto deveria ser pelo direito de aprender que todas as crianças possuem, todavia, em muitos casos, são os docentes que não possuem preparo adequado e desconhecem as formas para fazer valer este direito.

Comumente, o imigrante ou o estrangeiro é tratado como aquele que não possui raízes no grupo social e não pertence ao país. Nos pautamos nas considerações de Simmel (1983) ao compreendermos que o estrangeiro é aquele que não pertencia, veio e ficou; aquele que não vai embora, mas não está de passagem apenas.

Bezerra (2016, p.24) considera que a imigração traz em seu bojo um dado relevante no tocante ao aspecto da infância, pois as crianças demonstram alterações emocionais e comportamentais como marca das experiências traumáticas associadas à imigração forçada. Segundo a autora

Frutos do deslocamento, as crianças imigrantes têm sua mente posta em movimento. Sentimentos, ideias, comportamentos que têm o curso modificado de forma tão abrupta quanto o abalo inesperado do terremoto. Experiências traumáticas que irrompem o psiquismo, o luto das perdas que deprime e angustia, as marcas da violência silenciada que fazem o corpo 
falar na dor. É evidente a demanda por fortalezas que surjam a proteger o psiquismo. E é notório, também, que metáforas não faltam para associar às intempéries vividas pela mente humana - infantil -, daqueles que experienciam a imigração forçada. A sofrida realidade da saúde mental desses pequenos, contudo, não cabe ser romanceada. (p.38)

O Estatuto do Estrangeiro (Lei 6.815/80) estabeleceu diretrizes gerais sobre a situação jurídica dos imigrantes no Brasil, mas a Constituição Federal buscou garantir os direitos humanos fundamentais, incluindo o direito à educação que deve ser garantido pelo Estado. 0 texto constitucional é claro quanto a obrigatoriedade do Estado em garantir acesso à educação gratuita para pessoas na faixa etária entre quatro dezessete anos, inclusive para quem está indocumentado.

A Lei n.13.445/20175 , mais conhecida como a Lei do Imigrante, facilitou o processo de legalização do imigrante e repudia expressamente a discriminação e a xenofobia, no entanto, na prática, muitas vezes a lei não é conhecida pelo próprio imigrante. 0 que se estabelece comumente como prática nas escolas brasileiras é a rejeição e negação da inclusão dos estudantes imigrantes. Dessa forma, a imigração é estabelecida como um problema social, ou uma questão oriunda da relação entre um grupo social e suas tensões (os imigrantes e a questão do emprego/desemprego, a habitação, os filhos, bem como sua formação, os direitos) e, desta maneira, são construídas as "representações coletivas" sobre a imigração e o imigrante (Sayad, 1998, p.56)

O “ideal” teria sido que, assim definido, o imigrante fosse uma pura máquina, um sistema integrado de alavancas, mas, neste caso como em qualquer outro, "uma vez que o imigrante não é puro espírito" - sabemos disso há muito tempo - e uma vez que o imigrante não é puramente mecânico, é forçoso conceder-lhe um mínimo. Assim, como trabalhador, é preciso que seja alojado, mas então o pior dos alojamentos (que ele consegue sozinho) é amplamente suficiente; como doente, é preciso que seja tratado (isso por ele mesmo, e talvez muito mais para a segurança dos "outros"), mas que seja da forma mais rápida e mais econômica, sem tomar sempre o tempo e o cuidado que uma situação particular requer, principalmente no caso de doenças mentais (que, em sua maioria, são de origem sociológica ou ao menos comportam uma importante dimensão sociológica); o mais das vezes casado e pai de família, não seria possível proibi-lo de trazer para junto de si, dentro de certos limites, e sob certas condições, sua mulher e seus filhos - não se poderia nem mesmo impedi-lo indefinidamente de fazê-lo, principalmente quando manifesta tal desejo [...]

5 http://www.planalto.gov.br/ccivil_03/_ato2015-2018/2017/lei/l13445.htm 
Na esteira teórica de Sayad, compreendemos que a política em execução em termos de imigração é precisamente uma completa ausência de política, o que denota a cumplicidade com a visão capitalista que se tem do imigrante, importando apenas que este representa mão-de-obra barata que sofre pela precarização e desqualificação de seu trabalho.

A Lei de Diretrizes e Bases da Educação - LDB trata do dever à educação, no entanto não considera, especificamente, a educação da criança imigrante.

Art. $2^{\circ} \mathrm{A}$ educação, dever da família e do Estado, inspirada nos princípios de liberdade e nos ideais de solidariedade humana, tem por finalidade o pleno desenvolvimento do educando, seu preparo para o exercício da cidadania e sua qualificação para o trabalho

O artigo citado torna mais clara a compreensão de como a Lei aborda a educação como dever da família e do Estado, que deve ser inspirada nos princípios de liberdade e nos ideais de solidariedade humana, tendo por finalidade o pleno desenvolvimento do educando, seu preparo para o exercício da cidadania e sua qualificação para o trabalho (Art. $2^{\circ}$ ). Todavia, a Lei também reafirma questões abordadas por nós, no que diz respeito ao direito das crianças, ao incluir (Art. $3^{\circ}$ ) que o ensino será ministrado com base em diferentes princípios, e, dentre eles, podemos destacar: a igualdade de condições para o acesso e permanência na escola; a pluralismo de ideias e de concepções pedagógicas e o respeito à liberdade e apreço à tolerância. Nos parece incoerente imaginar uma escola que não siga esses princípios ao receber os alunos imigrantes com diferentes origens, histórias e saberes. Seguindo a mesma tendência, temos no Conselho Nacional dos Direitos da Criança e do Adolescente, a Resolução n.169 de novembro de 2014, que estabelece que crianças e adolescentes devem ser tratados de forma cuidadosa e sensível levando-se em consideração - no caso da criança imigrante - suas particularidades em relação a idade, estágio de desenvolvimento, desejos, identidade de gênero, orientação sexual, etnia, cultura, religião, formação linguística, condições socioeconômicas, status de refugiado ou imigrante, bem como as necessidades especiais de saúde e assistência, dentre outras. Para que isso aconteça, o documento estabelece que os profissionais responsáveis pelo atendimento de crianças e adolescentes considerem essas diferenças, assim como com as especificidades inerentes à matéria.

O objetivo ao abordar alguns aspetos legais é refletir brevemente a respeito da importância da legislação brasileira em assegurar o acesso de imigrantes à escola pública, entretanto não podemos afirmar que isto represente a verdadeira inclusão desses estudantes. Os imigrantes sofrem 
pela falta de um planejamento pedagógico coerente com suas necessidades, e, apesar de poderem se matricular, o que encontram na maior parte das vezes, são escolas que não possuem professores com formação adequada para este atendimento. Pode-se afirmar que, segundo especialistas da área, temos uma legislação avançada, entretanto, não garante que, na prática, as crianças tenham seu direito garantido de forma inclusiva e não somente com a garantia de uma vaga na escola.

Muitos desses estudantes não são acol hidos verdadeiramente e, nesse sentido, sem uma formação necessária, os docentes não conseguem desenvolver um trabalho que proporcione aprendizagens por meio da construção de conhecimentos (Rodrigues, 2016) considerando as diferenças culturais e de linguagem. Para a autora, a troca de informações pode beneficiar as crianças brasileiras que aprendem com as estrangeiras e vice-versa. Ressalta que, no entanto, é necessário que haja preparação dos professores nesse sentido e isto ainda não é realidade nos cursos de formação brasileiros.

O interesse nesta temática se relaciona também com experiências profissionais de uma das autoras em duas universidades públicas do Rio de Janeiro, em cursos de formação de professores (licenciatura em pedagogia) onde foi possível perceber que a formação inicial ainda é muito tímida no que diz respeito aos estudantes que chegam à universidade como imigrantes. Por outro lado, na formação inicial, os estudantes de pedagogia preparam-se para atuar no Ensino Fundamental e são eles que futuramente assumirão o papel de professores das crianças imigrantes, no entanto, esta realidade ainda não é problematizada nas salas de aula do ensino superior.

Nesse sentido, Oliveira (2016) ressalta que a política brasileira para o acesso de imigrantes é considerada avançada, entretanto, apesar de haver uma facilidade para efetivar a matrícula de uma criança imigrante, não temos um sistema público de ensino - municipal e estadual - preparado para receber esses estudantes, nem mesmo um planejamento pedagógico com esse fim. Além disso, os cursos de licenciatura voltados para a formação de professores não possuem disciplinas específicas para este fim, o que não contribui com a prática desses docentes ao receberem alunos imigrantes.

Desta forma, o desenvolvimento cognitivo e emocional dessas crianças é comprometido e o que percebemos na prática, é que a legislação obriga as escolas a receberem os filhos de imigrantes em virtude do direito universal, entretanto as crianças não vivenciam um processo de inclusão no meio educacional. 
Essa reflexão é compartilhada por Magalhães (2010) que reflete como alguns aspectos da condição do imigrante e da dinâmica do entorno afetam o ambiente escolar. A autora destaca elementos importantes ao buscarmos compreender os aspectos envolvidos na educação dos imigrantes, como o silêncio e a timidez dos estudantes, que passam muitas vezes por invisíveis. Defende que a invisibilidade destes estudantes se relaciona com a questão da ilegalidade, pois alguns deles buscam se proteger e há uma tendência das pessoas em não os enxergar, apesar de conviverem no mesmo bairro ou na mesma escola. Consideramos, como a autora, que escola brasileira insere o estudante no contexto escolar, no entanto, pouco promove a aprendizagem e desafia a promoção dos direitos humanos, ressaltado em inúmeros relatos de preconceito, discriminação e violência.

Grande parte dos estudantes se isola ao sofrer a experiência da discriminação e do preconceito, excluindo-se dos processos coletivos de aprendizagem e se colocando à margem do grupo social no qual deveria ser incluído a fim de criar a sua nova rede de relações. No ambiente escolar os estudantes deveriam ser estimulados a refletir sobre as diferenças e compreender as particularidades dos diferentes grupos que a escola recebe, trabalhando o respeito mútuo.

Podemos fazer uma analogia entre esse isolamento e o que Kristeva (1994, p.15) trata como o afastamento daquele que não pertence a lugar nenhum, nenhum tempo, carregando o sentimento de origem perdida e do enraizamento impossível.

A indiferença é a carapaça do estrangeiro: insensível, distante, no fundo ele parece fora do alcance das agressões que, contudo, sente com a vulnerabilidade de uma medusa. É que o afastamento onde o mantemos corresponde àquele em que ele próprio se aloja, recuando até o centro indolor daquilo que chamamos de alma, essa humildade que, definitivamente, constitui-se de uma nítida brutalidade.

De maneira semelhante, podemos abordar a questão das crianças que são matriculadas em escolas brasileiras, sem acolhimento e inclusão no processo educativo, gerando desinteresse e repetência, mesmo que o estudante frequente todas as aulas assiduamente. Essa situação gera desentendimentos entre os professores e a família, e, esta última, custa a compreender as particularidades deste processo e a dificuldade dos seus progenitores em desenvolver-se no ambiente educativo. As crianças, comumente se isolam e são tratadas como estudantes com necessidades especiais educativas. 
Um estudo sobre crianças de famílias bolivianas, educandos na rede pública de São Paulo (Liberato \& Lokoi, 2014), demonstra que não há apenas um completo estranhamento em relação aos hábitos e feições indígenas dos bolivianos, mas também um desconhecimento da história e das aproximações entre bolivianos e brasileiros, bem como questões emblemáticas que devem ser revistas acerca dos currículos e do projeto pedagógico das escolas, no sentido de incluir e mobilizar para aprendizagem todos os estudantes, independente da nacionalidade Segundo as autoras, particularmente nas famílias bolivianas, há uma cobrança intensa em relação aos estudos dos filhos que dificilmente faltam à escola e que possuem um alto nível de exigência dos pais, que classificam as escolas brasileiras como fracas e com poucas lições. Ainda assim, esses pais depositam grandes expectativas em relação aos estudos dos filhos nas escolas públicas brasileiras (Gonçalves,2016).

Destaca-se que são inúmeros os casos descritos na bibliografia a respeito de preconceito e discriminação com os imigrantes que chegam ao Brasil e, principalmente, na cidade de São Paulo, que continua a receber um número considerável de imigrantes e, todavia, há uma cultura xenófoba que classifica os imigrantes bolivianos, por exemplo, como "índios" e "ladrões de empregos". A maior parte dos estudantes sofre com atitudes agressivas por parte dos colegas, com discursos de ódio e racismo que estimulam intensamente o bullying (Salgado, 2013).

Em nosso caminhar por entre a literatura, encontramos outros estudos, dentre eles, uma pesquisa desenvolvida com crianças haitianas residentes em Porto Velho, no estado de Rondônia. Em suas considerações, os autores apontam fatores que dificultam a inclusão no meio educacional e, consequentemente, a aprendizagem das crianças haitianas. Podemos afirmar que os pontos discutidos se assemelham em várias questões com outros estudos: dificuldades linguísticas, aceitação por parte das outras crianças, falta de preparo entre os docentes, no sentido de promover a verdadeira inclusão desses educandos no processo educativo, de forma plena.

Ao ingressar no novo país a criança haitiana, assim como qualquer outro imigrante, se não souber a língua deste novo local necessitará imediatamente aprendê-la para que assim ela possa se comunicar com as pessoas. Os primeiros meses são sempre os mais difíceis, pois a língua, a cultura e o sistema em que está organizado o país é diferente do país de onde veio. Inserir-se em uma nova sociedade requer tempo, o impacto causado por essa nova realidade faz com que o imigrante de um modo geral, principalmente as crianças, se fechem. 0 que é natural, mas tem caráter negativo para a inserção, especialmente quando se quer aprender uma nova língua. (Santos et al., 2015, p. 48). 
Nesse caso, o ensino da língua portuguesa torna-se mais complexo e traz em seu bojo questões particulares desta criança que precisa aprendêla para conseguir comunicar-se com as outras pessoas e, neste sentido, o professor precisa estar atento às dificuldades inerentes ao processo de aprendizagem, levando em conta esses aspectos e apropriando-se da noção de alteridade, percebendo com isso que há um outro na relação (Santos et al., 2015, p.50).

Novamente encontramos 0 isolamento como uma estratégia utilizada pelas crianças, que não se sentem incluídas naquele grupo social, pois encontram inúmeras dificuldades de adaptação ao novo país, sentem-se fragilizadas e, ainda que inconscientemente, buscam a invisibilidade como forma de se proteger da discriminação. Tal cenário se perpetua no contexto educativo do nosso país e se caracteriza como realidade percebida em escolas localizadas em outros estados brasileiros.

Bezerra (2016) apresenta um estudo onde analisa a saúde mental infantil no contexto da imigração e aponta que há uma carência de publicações nacionais que abordem o assunto. Abordando os impactos psicológicos oriundos da imigração, o estudo buscou compreender essa questão, considerando crianças imigrantes com faixa etária de 06 a 12 anos, moradoras de Florianópolis. As conclusões apontam para a confirmação do sofrimento psíquico que as crianças imigrantes vivenciam e para a necessidade de problematizar esta temática nos espaços acadêmicos. A autora nos alerta para a necessidade de ampliar os espaços de discussão dessa questão, considerando escolas públicas e privadas, além de instituições governamentais que atuam no trabalho com crianças imigrantes no Brasil. Ressalta que o estudo buscou fortalecer a construção de práticas que garantam a atenção devida à saúde mental dos imigrantes, garantindo seu direito à infância e mantendo um olhar sensível para a singularidade dos processos em que eles estão envolvidos, bem como suas diferenças culturais.

O minidocumentário "Migração como direito humano: rompendo o vínculo com o trabalho escravo", da ONG Repórter Brasil ${ }^{6}$, aborda os desafios das escolas no atendimento à população imigrante matriculada na cidade de São Paulo e torna públicos alguns discursos construídos por meio das narrativas infantis. Em um trecho do minidocumentário, uma criança entrevistada afirma ter sofrido preconceito por suas características físicas e por ser estrangeira: "No começo eu era discriminado pra caramba, ficava até no fundo da escola, no fundo da sala". A narrativa foi construída por um estudante boliviano e retrata uma das grandes dificuldades dessas crianças ao chegarem ao novo

6 "Migração como direito humano: rompendo o vínculo com o trabalho escravo" https://vimeo.com/219155621 
país e serem recebidos no sistema educacional: a discriminação. As crianças que já se encontram na escola demonstram comportamentos que, na maioria das vezes, são? de hostilidade e preconceito com os imigrantes. Podemos inferir que esses comportamentos nascem no próprio ambiente familiar onde ouvem e presenciam atitudes com características de xenofobia.

O minidocumentário foi produzido no âmbito do "Programa Escravo, nem pensar!", que aborda aspectos relacionados os desafios enfrentados pelas escolas públicas paulistas no atendimento à população imigrante matriculada. Nele são apresentadas entrevistas com filhos de imigrantes e de brasileiros, além de educadores envolvidos no processo, buscando traçar um panorama sobre direitos humanos e imigração no Brasil. O que vemos nas narrativas são alunos que têm sua origem em outros países e relatam dor e sofrimento, pela maneira desrespeitosa com que são tratados, mesmo sendo cada vez mais presentes no cotidiano escolar paulista. Dados do Censo Escolar de São Paulo indicam que, entre 2015 a 2016,7 3.691 alunos de 62 nacionalidades foram matriculados na rede municipal. Dentre eles, 184 venezuelanos - índice que poderá ser cada vez maior, devido à grave crise social, política e econômica na Venezuela.

Em relação à situação escolar de crianças imigrantes transnacionais no Rio de Janeiro, a revisão da literatura tem mostrado uma grande carência de investigações nesse sentido. Encontramos estudos que tratam de infância e migração em diferentes estados brasileiros, especialmente em São Paulo (Zimermann, 2017; Dias e Neto, 2019). No entanto, o percurso das pesquisadoras vem mostrando dificuldades no que diz respeito a publicações sobre crianças de famílias migrantes matriculadas na rede pública municipal do Rio de Janeiro, pela escassez de documentos que abordem o assunto, o que causa impedimentos quanto ao estudo dos grupos migratórios na cidade.

\section{Cenário empírico}

Nosso cenário empírico para este estudo constitui-se por meio de momentos distintos: a atividade voluntária de uma das autoras com as crianças imigrantes oriundas do Equador, o acompanhamento das atividades pedagógicas realizadas por eles em casa junto com suas mães (o dever de casa) e a participação em algumas reuniões de pais nas escolas dessas crianças juntamente com suas mães. Além disso, a interação com os professores de escolas públicas e privadas do Rio de Janeiro durante aulas ministradas

\footnotetext{
${ }^{7}$ http://www.educacao.sp.gov.br/cima/consultas/censo-escolar/
} 
no curso de Especialização sobre Inclusão, da Faculdade de Educação da UFRJ, na qual as autoras discutiram os desafios colocados aos professores na recepção e apoio a crianças e adolescentes imigrantes transnacionais.

O trabalho voluntário teve início no ano de 2017, com grupos de crianças migrantes transnacionais que moram em um bairro da zona sul carioca, onde seus pais trabalham como vendedores ambulantes. A maior parte é de origem equatoriana, mas existe uma família cuja mãe é peruana e o núcleo familiar materno é oriundo do Peru. As crianças possuem idades que variam entre dois e nove anos e cada família chegou ao Brasil em um momento diferente, todavia elas se organizaram e compartilharam ajuda na vinda de outros familiares. Para localizar cronologicamente a chegada dessas crianças ao Brasil podemos afirmar que isto se deu nos últimos quatro anos.

A proposta de voluntariado desenvolvida por uma das autoras deste artigo na praia de Copacabana, foi criada com a intenção de contar histórias e estimular a leitura literária, além de contribuir com o aprendizado da língua portuguesa, visto que a maioria é bilíngue. 0 que percebemos no convívio é que as crianças são falantes de português na escola, entretanto no ambiente familiar o que prevalece é a língua materna (algumas vezes espanhol e, em alguns casos, uma língua quíchua) ${ }^{8}$. Interessante notar que, quando estão nas atividades coletivas com a presença da educadora que desenvolve este trabalho, eles se comunicam em português, entretanto se uma das mães se aproximar do grupo eles conversam em sua língua materna. Diante da insistência da educadora para que falem em espanhol com ela, eles sorriem e dizem que não falam mais espanhol. Parece haver uma separação muito clara dos espaços e das "licenças" para utilizar determinada língua, como um código que permite a prática dialógica adequada ao ambiente escolar e fora dele.

Esta atividade acontece semanalmente em um espaço ao ar livre onde é possível reunir as crianças bem próximo dos seus responsáveis, com exceção dos dias em que há chuva. As atividades organizadas são variadas e com apoio de materiais e brinquedos diversificados que possam estimular a interação, a criatividade e a aprendizagem. 0 público é diversificado, com crianças de idades que variam entre dois e nove anos.

8 quíchua, também chamado de quechua ou quéchua, é uma importante família de línguas indígenas da América do Sul, ainda hoje falada por cerca de dez milhões de pessoas de diversos grupos étnicos da Argentina, Bolívia, Chile, Colômbia, Equador e Peru ao longo dos Andes. Possui vários dialetos inteligíveis entre si. 


\section{A construção dos dados e os sujeitos da pesquisa}

Para esta pesquisa, tomamos como referência metodológica os estudos de cunho qualitativo, onde propomos um caminho investigativo que é construído com rodas de conversa com as crianças e as suas mães. Nosso objetivo é compreender como as narrativas podem se constituir como dados de pesquisa e, nos colocando no lugar de pesquisadores que buscam a construção de diálogos e a compreensão de todos os momentos envolvidos neste processo.

Durante as atividades desenvolvidas com as crianças e suas famílias, são feitos registros por meio de gravações de áudios e, após a atividade, um caderno de campo é utilizado para impressões e planejamento para próximas atividades. Esta etapa representa a primeira parte da coleta de dados e estamos organizando este material de maneira a elaborar táticas de análise escolhendo episódios enunciativos significativos para a análise. Nas narrativas construídas percebemos interações discursivas que propiciam dados subjetivos e relevantes para um estudo qualitativo.

Segundo Martins, Jansen e Terreri (2005), quando tratamos a pesquisa como interação discursiva, devemos considerar que os dados são construídos em diferentes níveis. No caso deste estudo, utilizamos gravações de áudio e algumas videogravações feitas em um período anterior ao delineamento da pesquisa e outras que estão sendo produzidas no decorrer do estudo. Este material representa, no nosso entendimento, o primeiro nível da construção dos dados da pesquisa. Os registros no caderno de campo com a escuta dos áudios foram a base para selecionar trechos para a análise. Os nomes foram trocados por pseudônimos, apesar de haver autorização para uso da imagem e do som.

Durante a pesquisa, é possível observar cada narrativa e os escritos do caderno de campo usado para registro e memória das atividades. Estes registros contribuem para caracterizar e descrever cada ação analisada. 0 material gravado possibilita uma análise mais detalhada das táticas adotadas pelos narradores. Uma primeira análise das gravações está sendo realizada para que seja possível selecionar o material empírico. A intenção é compreender como as crianças e suas mães veem a escola e o acolhimento e inclusão desse alunado. A escuta atenta das gravações busca também entender os recursos (linguísticos ou não) que eles lançam mão na tentativa de facilitar o entendimento da pesquisadora.

Em relação à coleta do material empírico, consideramos que a utilização de videogravações e gravações de áudios pode trazer questionamentos a respeito da possibilidade de apresentar um caráter intrusivo, entretanto, 
acreditamos que a presença da pesquisadora no cenário empírico não o modificou, mas sim o constituiu, pois este cenário não é externo e existe, enquanto tal, a partir da presença e do interesse do pesquisador (Martins, 2006). Importante ressaltar que existem momentos que serão analisados: as conversas sobre a escola e o desenvolvimento das crianças (durante atividades na praia) e as trocas de mensagens para realização dos deveres de casa, feita pelo aplicativo de mensagens instantâneas e chamadas de voz WhatsApp. Essas mensagens são compartilhadas entre a pesquisadora e as mães, durante a noite e/ou finais de semana, a fim de auxiliar na realização das tarefas enviadas pela professora, em virtude da dificuldade na compreensão tanto da língua portuguesa e quanto da proposta pedagógica.

Para fins de análise, os subsídios teóricos foram encontrados no campo da linguagem, considerando a produção de enunciações na perspectiva dos estudos de Bakhtin (2003, 2004), pois considera-se que os sujeitos deste estudo são produtores de sentidos que são carregados de ideologia, e isto pressupõe o entendimento acerca da linguagem e suas relações com esses sujeitos. Nos apoiamos na compreensão bakhtiniana de linguagem que trata a dialogicidade de maneira bem mais ampla do que apenas um elemento estruturante da comunicação,e leva ao entendimento de que quem fala para alguém, estrutura este discurso esperando uma determinada resposta do seu interlocutor. Desta maneira, toda palavra tem origem em um ser social e se dirige a outro ser social e, nesta interação, são produzidos novos sentidos e novos enunciados. As palavras possuem representação social, demonstram embates ideológicos e conflitos do sistema social em que estão inseridas, bem como dos sujeitos envolvidos. Bakhtin (2004) considera a interação como princípio fundamental da linguagem, que se forma por meio da construção de enunciados orais e/ou escritos, resultantes da atividade humana, e desta forma é constituída em meio a contextos histórico-sociais.

As conversas são organizadas por meio de algumas perguntas norteadoras que são feitas pela pesquisadora: "Como foi a semana na escola? "O que fizeram?" e, a partir disso, os diálogos são construídos. A análise das narrativas está ainda em curso. Apesar disso, temos algumas reflexões preliminares a partir dos apontamentos de professores matriculados no Curso de Especialização da UFRJ ao serem colocados na posição imaginária de responsáveis pela recepção de alunos estrangeiros, quando apontaram caminhos possíveis, como o trabalho na perspectiva de um ensino que fortaleça o bilinguismo que as crianças já trazem em virtude de falarem a sua língua materna e o português ensinado na escola. Consideram importante o preparo do corpo docente e gestor para recepção dos pais, buscando a inclusão deles bem como das crianças, em uma perspectiva de articulação dessas ações com o projeto político pedagógico da escola. 


\section{Reflexões e alguns resultados preliminares}

Nos relatos das mães sempre aparecem expressões carregadas de sentimentos de contrariedade e insatisfação quanto à maneira como são recebidas na escola, em reuniões de pais e pela maneira como as observações são feitas ao se tratar do desenvolvimento das crianças. Algumas mães dizem não compreender o que falam as professoras, mas não fazem perguntas, por serem tímidas ou tentarem se tornar invisíveis, tal como a tática utilizada por suas crianças, e considerarem isso como uma forma de exposição para elas e para seus filhos. Afirmam que preferem o silêncio tentar "descobrir" depois quais foram as orientações. Quando indagada sobre essas observações feitas a respeito de seu filho, Maria afirma que não compreende o que a professora fala e o filho também não entende o que a professora solicita nas atividades extraclasse.

Neste grupo, temos cerca de oito mães - nomeadas aqui como Juliana, Renata, Fabiana, Mercedes, Lúcia, Esthela, Luzmila e Maria - que possuem idades variadas entre 21 e 29 anos e são oriundas basicamente de duas regiões distintas no Equador: Otavalo e Quito e migraram, em sua maioria, já casadas ou se uniram ao companheiro assim que chagaram aqui no Brasil. Há uma característica fortemente marcada pela aproximação com outras famílias equatorianas e pelos relacionamentos afetivos com homens equatorianos. Algumas possuem outras redes de ajuda estabelecidas na comunidade onde vivem, por meio de vínculos construídos em grupos religiosos ou no espaço onde trabalham (na rua), no entanto isto não é comum.

No convívio com as mães, percebemos que são muito cuidadosas com seus filhos e, mesmo vivendo em situação de vulnerabilidade social buscam cuidar das crianças com muito zelo. Elas contribuírem igualmente com a renda familiar e ainda são as responsáveis pelos cuidados com a casa e as crianças.

Os estudos desenvolvidos sobre imigração propiciam mudanças - ainda que efetivadas a longo prazo - nas práticas que foram construídas nos espaços sociais, com imigrantes adultos ou ainda na infância. Compartilhamos as mesmas proposições de Mezzadra (2012, p. 73) que acredita na adoção de uma postura que envolva uma "sensibilidade diferente" para olhar a questão das migrações. Significa olhar os movimentos e os conflitos migratórios em outros termos, que priorizem as práticas subjetivas, os desejos, as expectativas, e os comportamentos dos próprios imigrantes. Entretanto, segundo o autor, isso não significa "romantizar" a imigração, mas considerar a ambivalência dessas práticas, bem como sua subjetividade no âmbito do fenômeno das migrações. Na esteira teórica de Mezzadra, entendemos que 
novos dispositivos devem ser criados, diferenciando-se dos movimentos sociais onde predominam dominação e exploração, buscando novas práticas de liberdade e igualdade.

O Brasil possui uma longa história com momentos diferentes e inserções distintas de imigrantes, todavia essa história foi sempre carregada de sentidos ideológicos marcados pela cultura capitalista e por uma visão do imigrante enquanto mão-de-obra barata com possibilidades de precarização de condições trabalhistas e de permanência no país. Isso é discutido por autores que se debruçam sobre a questão da imigração (Sayad, 1998; Grosfoguel, 2007; Mezzadra, 2012), tratando-a de forma crítica, no sentido de ressaltar como ela é constituída como força de trabalho barata. Esta relação de trabalho pode ser tratada como "imagem da decomposição e fragmentação do trabalho determinada pelo capitalismo contemporâneo, por obra e graça do neoliberalismo e do processo de financeirização" (Mezzadra,2012, p.73). Nesse sentido, as crianças, como já foi abordado, tornam-se ainda mais vulneráveis às práticas de trabalho escravo e de rejeição nos espaços escolares. Reafirmamos que se trata de aceitar os imigrantes como cidadãos, pois eles agem e vivem como cidadãos, inseridos nos espaços enquanto trabalhadores e estudantes, mesmo sem documentos ou inclusão nestes grupos (Mezzadra, 2012).

Nas palavras do professor ElHajji (2017), o Brasil é um país xenófobo e, nesse sentido, consideramos também que as práticas construídas cotidianamente para com os grupos de imigrantes são extremamente carregadas de sentidos preconceituosos, discriminatórios, excludentes e pautados na xenofobia. As crianças, nosso interesse principal neste texto, são vítimas destes processos que se constituem nos espaços sociais, incluindo a escola, onde passam a maior parte do tempo de que usufruem em seu cotidiano. Nesses espaços as relações construídas, ao invés de propiciar inclusão reforçam a exclusão e a discriminação, por meio de atitudes que podem ser classificadas também como bullying ${ }^{9}$. Esse processo dificulta ou até impede o desenvolvimento integral das crianças, além de sua integração plena enquanto estudantes, nos processos escolares didático-pedagógicos. Consideramos apropriado destacar um trecho da palestra de Martins (2013) durante o IV Fórum de Migrações - realizado no Rio de Janeiro - quando apresentou uma análise dos comentários de internautas em portais de notícias, onde ressaltou que identificou falas racistas e xenófobas como atitudes comumente encontradas

${ }^{9}$ Bullying,termo utilizado para descrever atos de violência física ou psicológica, intencionais e repetidos, praticados por um indivíduo ou grupo de indivíduos causando dor e angústia, sendo executadas dentro de uma relação desigual de poder. É um problema mundial, sendo que a agressão física ou moral repetitiva deixa sequelas psicológicas na pessoa atingida. 
nestes espaços virtuais. Segundo a professora - integrante da Comissão de Altos Estudos do Programa Memórias Reveladas da Casa Civil da Presidência da República - ainda temos memórias internalizadas de crenças criadas ao longo dos anos em que se perdurou a triste realidade da sociedade escravocrata no Brasil, o que reforça estereótipos preconceituosos e discriminatórios que são retratados nesses discursos construídos em diferentes espaços, inclusive aqueles que são virtuais. Como aponta Martins (2013), "Os imigrantes latinos, angolanos e chineses são muitas vezes apontados como responsáveis pelo tráfico de drogas em favelas e ocupantes sem merecimento de vagas no SUS e na educação básica pública".

A xenofobia certamente atinge as crianças, como ilustra a venezuela Alejandra, de 11 anos, em entrevista ao grupo DIASPOTICS: "as meninas da minha escola dizem que não posso participar do Grêmio porque sou estrangeira. Fico triste". Além da xenofobia, há também o racismo, bastante institucionalizado em nosso país, mas pouco assumido. Kongo (2017) acrescenta à fala de Martins alguns dos estereótipos aos quais os imigrantes transnacionais estão sujeitos:

Só pelo fato de sermos africanos, somos considerados analfabetos. Pensam que não temos cultura, que não temos formação, que somos ignorantes. Só pelo fato de sermos árabes, pensam que somos terroristas. Pelo fato de sermos colombianos, acham que somos traficantes. (Kongo, 2017, p.13).

Os processos envolvidos em meio ao fenômeno da imigração são extremamente complexos e necessitam de estudos aprofundados guardadas as especificidades de cada questão envolvida. Nesse sentido, afirmamos que é necessário aprofundar o estudo acerca da inclusão das crianças imigrantes nas escolas brasileiras, buscando compreender em que sentido esses estudos podem ser tratados por um recorte que trate de infância e aprendizagem ou por meio da discussão a respeito da formação docente no Brasil. Talvez seja necessário o aprofundamento de ambos, em virtude da sua estreita relação, bem como as implicações disso para o desenvolvimento integral das crianças imigrantes. Ressaltamos que o processo de inclusão significa criar condições reais de desenvolvimento e aprendizagem, considerando a cultura dessas crianças, assim como suas histórias de vida, experiências e saberes. Outra questão importante nessa reflexão é a integração das famílias nos processos que permeiam e a vida escolar da criança, buscando inseri-los também nas discussões e práticas em que seus filhos estarão incluídos.

Os professores, ao receberem alunos imigrantes, são colocados em uma posição de comunicadores interculturais, sem o terem solicitado. De que competências precisam? Como desenvolvê-las? Bastos (2014), a respeito das competências de comunicação intercultural, enxerga um contínuo apren- 
dizado, visão compartilhada por nós, dentro de um espectro que parte de uma perspectiva mais etnocêntrica para uma mais etnorrelativa. Propõe que os processos de desenvolvimento dessa competência passem não somente

pela informação / observação e interação, na perspectiva de King \& Baxter Magolda (in. Spitzberg \& Changnon, 2009), mas também, na nossa perspectiva, pela reflexão. Autores como Bennett (in. Ogay, 2000) e King \& Baxter Mongola (in. Spitzberg \& Changnon, 2009) elegem a empatia e 0 pluralismo cultural como características dos comunicadores interculturais maduros / competentes. (p.50)

Nessa "multidão" migrante há um número cada vez maior de sujeitos sociais que ainda precisam de condições para viver plenamente sua infância, muitas vezes interrompida pelo próprio processo de migração, onde são obrigadas a abandonar suas raízes em busca de novos caminhos junto de suas famílias. Consideramos que uma maneira de abordar essa questão é tratar como a tarefa essencial a construção de muitas "pontes" e destruição de muitas "barreiras" (Mezzadra, 2012).

As crianças precisam de condições socioeducativas apropriadas, o que consiste na garantia do direito universal à educação com condições para seu pleno desenvolvimento, o que inclui levar em consideração os aspectos socioemocionais que desempenham papel essencial no processo de inclusão das crianças e jovens imigrantes. Ademais, a escola tem um papel essencial como ponte, inclusive, das famílias aos possíveis programas de apoio à saúde mental das crianças e seus responsáveis.

Políticas públicas de acolhimento e apoio são imprescindíveis, mas precisam ser pensadas a partir da convergência de que nos fala Baumann (2001), pois, como afirma Jobana Moya Aramayo ${ }^{10}$

Se não se pensam as políticas públicas desde a interculturalidade, a população migrante nunca será realmente contemplada. A globalização quer que todos sejamos iguais, mas temos particularidades. Podemos valorizar essa diversidade e a partir dela construir algo novo.

10 “Jobana Moya Aramayo é mãe de Wayra e Fernando Osvaldo, imigrante da bolívia e ativista pela não-violência e pelos direitos das mulheres imigrantes. Fundadora da Equipe de Base Warmis - Convergência das Culturas". Disponível em https://bit.ly/2IF450U 


\section{Considerações (in)conclusivas}

O cenário educativo que apresentamos neste texto nos traz muitas inquietações e, diante de lacunas apontadas percebemos que é necessário ampliar a reflexão acerca dos processos de inclusão das crianças imigrantes no contexto educacional brasileiro. Perante tal questão ressaltamos que a legislação garante a matrícula dos estudantes nas unidades escolares, todavia não possibilita a inclusão almejada com todas as condições para o aprendizado integral. Nesse sentido, nos posicionamos em defesa do acesso à educação pública, gratuita, em uma perspectiva democrática e inclusiva.

Em nossas rodas de conversas com os professores buscamos estar atentas às narrativas construídas, bem como os sentidos dos discursos produzidos naquele contexto. Na maior parte do tempo há uma demonstração de desconhecimento de questões inerentes ao processo de chegada e permanência de refugiados e imigrantes no Brasil. Isto também possui uma implicação direta com a questão da inclusão das crianças pertencentes a esses grupos.

Indagados sobre o que consideram relevante para o momento da chegada dessas crianças ao ambiente escolar, afirmam que há um desconhecimento do perfil do novo estudante, bem como uma falta de informações acerca das famílias, sua cultura e sua história. Isso vem trazendo - na visão dos professores e das professoras - uma sucessão de equívocos no trato das questões cotidianas que atingem esse alunado. Questionados sobre as práticas que são construídas na escola, reconhecem a importância de compreender este processo e suas múltiplas complexidades, de modo a vislumbrar a potência do trabalho educativo. Todavia afirmam que, ao vivenciar a docência percebem que muitas vezes são tangenciados por um contexto social complexo que os afasta de uma prática comprometida com esse alunado diversificado. Corroboram nossas hipóteses acerca do cotidiano docente, quando nos falam da prática vivenciada, onde as dificuldades que se apresentam estão impulsionando o trabalho, mas também se caracterizam como elementos que impedem o caminhar visando à mudança.

Durante nosso percurso investigativo, buscamos avaliar as estratégias metodológicas, o que torna este processo desafiador e instigante. Compreendemos que este estudo deve ser construído por meio do método e pela nossa maneira particular de fazer pesquisa, o que em nossa compreensão se relaciona com a nossa postura de educadoras e com a maneira de entender o mundo. As rodas de conversas estão se configurando como forma de mergulhar na experiência, refletindo sobre o processo que se torna rico por meio da escuta do outro e das trocas compartilhadas. O que experimentamos com esta metodologia também nos estimula a repensar os processos educativos que envolvem aprender e ensinar. 


\section{Referências bibliográficas}

Bastos, M. (2014). A competência de comunicação intercultural: olhares sobre a natureza do conceito e suas dinâmicas de desenvolvimento. Cadernos do LALE. Série reflexões 6. Aveiro: UA Editora.

Baumann, G (2001). El enigma multicultural: un replanteamiento de las identidades nacionales, étnicas y religiosas. Capítulo 10: La praxis multicultural: lo banal y lo óptimo. Paidós Ibérica.

Bakhtin, M. (2003). Estética da Criação Verbal. São Paulo: Martins Fontes.

Bakhtin, M. (2004). Marxismo e Filosofia da Linguagem. São Paulo: Hucitec.

Bezerra, C. (2016) Distantes do Berço: impactos psicológicos da imigração na infância. Dissertação (mestrado) - Universidade Federal de Santa Catarina, Centro de Filosofia e Ciências Humanas, Programa de Pós-Graduação em Psicologia, Florianópolis. Disponível em https://bit.ly/2kOEyix

Bonadio, R. A. A. (2013). Transtorno de déficit de atenção / hiperatividade: diagnóstico da prática pedagógica. Maringá: Eduem.

Conselho nacional da criança e do adolescente (2014). Resolução n. 169 de 13.11.14. Disponível em https://bit.ly/2ID1kO0

Couto, M. (2015). Terra Sonâmbula. 1 ed. - São Paulo: Companhia de Bolso.

Dias, E., \& Neto, J. (2019). Diversidade cultural no espaço escolar: implicações no ensino, na aprendizagem e nos processos de subjetivação Cultural, Rev. Cient. EccoS, 48, 51-70.

Elhajji, M. (2017). Notas de Aula durante a realização da disciplina Comunicação, Identidade e Representações, segundo semestre. Programa de Pós-Graduação em Comunicação e Cultura da Escola de Comunicação (ECO) Universidade Federal do Rio de Janeiro.

Escudero, C. (2017). A imprensa imigrante do Rio de Janeiro. Caderno de Resumos do IV Simpósio de Pesquisa sobre Migrações. Rio de Janeiro: Escola de Comunicação - UFRJ.

Galina, V. F., Silva, T. B. B. D., Haydu, M., \& Martin, D. (2017). A saúde mental dos refugiados: um olhar sobre estudos qualitativos. Interface-Comunicação, Saúde, Educação, 21, 297-308.

Garcia, C. (2015). Infância e Diáspora: como sente - e como a escola pode receber - uma criança imigrante? Portal Aprendiz. Disponível em https://bit.ly/2m0l50t.

Gonçalves, C. (2016). O limiar entre ser boliviano e ser brasileiro: as identidades híbridas das crianças imigrantes na cidade de São Paulo. Anais do II Simpósio Internacional Pensar e Repensar a América Latina. São Paulo: Memorial da Resistência.

Grinberg, L., \& Grinberg, R. (1996). Migración y Exilio. Estudio psicoanalítico. Madrid: Biblioteca Nueva, S. L.

Grosfoguel, R. (2007). Migrantes coloniales caribenhos em los centros metropolitanos del sistema-mundo: los casos de Estados Unidos, Francia, Los Países Bajos y el Reino Unido. Serie Migraciones, n.13, Junio. Barcelona: Documentos CIDOB.

Kongo, C. (2017). O trabalho para os refugiados no Brasil - o olhar de um refugiado congolês. p. 12-13, dezembro. Pastoral do Migrante; Coletivo Rede Migração Rio (Orgs.). Presença do Migrante no Rio de Janeiro: O olhar do Imigrante. Rio de Janeiro: Scalabrini International Migration Network (SIMN). 
Kristeva, J. (1994). Estrangeiros para nós mesmos. Tradução de Maria Carlota Carvalho Gomes. Rio de Janeiro: Rocco.

Liberato, D., \& Lokoi, Z. (2014). Crianças bolivianas nas fronteiras da educação brasileira. Políticas Educativas, 7(2), 155-163.

Magalhães, G. (2010). Fronteiras do Direito Humano à Educação: um estudo sobre os imigrantes bolivianos nas escolas públicas de São Paulo. 184f. Dissertação (Mestrado) Faculdade de Educação, Universidade de São Paulo.

Martins, I. (2013). Novos imigrantes, velhos preconceitos. Resumo da palestra proferida durante o V Fórum de Imigração, de autoria de Irene Niskier. V Fórum de Imigração do Rio de Janeiro, 4 e 5 de dezembro, CFCH, Praia vermelha. Rio de Janeiro: UFRJ.

Martins, I., Jansen, M., \& Terreri, L. (2005). Mapas de eventos como ferramentas para a construção de dados na pesquisa qualitativa. Anais do IV Fórum Internacional de Investigação Qualitativa.

Martins, I. (2006). Dados como diálogo - construindo dados a partir de registros de observação de interações discursivas em salas de aula de ciências. In: A Pesquisa em Ensino de Ciências no Brasil e suas Metodologias. Ijuí: Editora Unijuí.

Mezzadra, S. (2012). Multidão e Migrações: a autonomia dos migrantes. Revista do programa de Pós-Graduação em Comunicação e Cultura da Escola de Comunicação da Universidade Federal do Rio de Janeiro, 2012.

Oliveira, C. (2016). Formar os Formadores. O estrangeiro. Disponível em: https://bit.ly/2ksSQsp

Park, M, \& Katsiaficas, C. (2019). Mitigating the Effects of Trauma among Young Children of Immigrants and Refugees: The Role of Early Childhood Programs. Washington, DC: Migration Policy Institute.

Rodrigues, L. (2016). Crianças Imigrantes enfrentam a barreira da língua e despreparo da rede de ensino. Comunica. Disponível em https://bit.ly/2kvqQnT

Salgado, D. (2013). Panorama atual da imigração boliviana. O estrangeiro. Disponível em https://bit.ly/2IDvDnq

Santos, A., Santos, M., Assis, W., \& Cotinguiba, M. (2015). Inserção sociocultural de haitianos em Porto Velho: o ensino e aprendizado da língua portuguesa. Revista Igarapé, 1(5), 43-53.

Sayad, A. (1998). O que é um imigrante. In: A imigração ou os paradoxos da alteridade. Tradução Cristina Murachco. São Paulo: EDUSP.

Simmel, G. (1983). O Estrangeiro. In: MORAES F, Evaristo (Org.). Sociologia. São Paulo: Ática.

Yousafzai, M, \& Welch, L. (2019). We are displaced. My journey and stories from refugee girls around de world. New York, Boston: Little, Brown and Company.

Zimerman, A. (Org). (2017). Impacto dos fluxos imigratórios recentes no Brasil. 113p. (Desigualdade regional e as políticas públicas; v. 11. Santo André: Universidade Federal do ABC. Disponível em http://biblioteca.ufabc.edu.br/ 